\title{
Analisis Pengaruh Slice Thickness Terhadap Kualitas Citra Pesawat CT Scan Di RSUD Bali Mandara
}

\section{The Analysis of the Effect of Slice Thickness of Phantom on Image Quality of CT Scan at RSUD Bali Mandara}

\author{
Ida Ayu Putu Aristia Hutami ${ }^{1 *}$, Gusti Ngurah Sutapa ${ }^{1}$, Ida Bagus Alit Paramarta ${ }^{1}$ \\ ${ }^{1}$ Jurusan Fisika, Fakultas Matematika dan Ilmu Pengetahuan Alam, Universitas Udayana, Kampus Bukit \\ Jimbaran, Badung, Bali, Indonesia 80361 \\ Email: *aristiahutami@student.unud.ac.id; sutapafis97@unud.ac.id; paramarta@unud.ac.id
}

\begin{abstract}
Abstrak - Telah diteliti pengaruh slice thickness (ketebalan irisan) terhadap kualitas citra dengan metode parameter Contrast to Noise Ratio (CNR) menggunakan phantom Toshiba (TOS). Variasi slice thickness yang digunakan yaitu 1, 2, 3, 4, 6, dan $8 \mathrm{~mm}$. Tegangan tabung dan arus waktu sinar-X yang digunakan adalah $80 \mathrm{kV}$ dan $100 \mathrm{mAs}$, sesuai dengan protokol pemeriksaan kepala pasien. Analisis pengaruh variasi slice thickness terhadap CNR ditentukan dengan uji regresi sederhana menggunakan kurva eksponensial. Hasil uji tersebut menunjukkan variasi slice thickness mempengaruhi nilai CNR, dimana semakin besar slice thickness maka nilai CNR semakin besar dan kualitas citra yang semakin baik.
\end{abstract}

Kata kunci: Ketebalan irisan, Contrast to Noise Ratio, Region of Interest, Computed Tomography

\begin{abstract}
It has been investigated the effect of slice thickness on image quality with the Contrast to Noise Ratio (CNR) parameter method using a Toshiba (TOS) phantom. The variations in the slice thickness used were 1, 2, 3, 4, 6 and $8 \mathrm{~mm}$. The X-ray tube voltage and the X-ray current time used were $80 \mathrm{kV}$, and $100 \mathrm{mAs}$, which following the patient head examination protocol. The analysis of the effect of slice thickness on CNR values is determined with a simple regression test with an exponential curve.. The test results showed that variations in slice thickness affect CNR values, where the greater the slice thickness then the CNR value would be higher and better the image quality
\end{abstract}

Key words: Slice thickness, Contrast to Noise Ratio, Region of Interest, Computed Tomography.

\section{Pendahuluan}

CT Scan (Computed Tomography Scan) merupakan alat penunjang diagnostik yang menggunakan sinar-X melalui teknik tomografi dan komputerisasi modern untuk pemeriksaan organ tubuh manusia. Sejak diperkenalkan untuk pertama kali pada tahun 1972, CT Scan telah berkembang menjadi alat pencitraan diagnostik yang sangat penting untuk beberapa aplikasi medis. Kemajuan pencitraan teknologi CT Scan adalah perbaikan kualitas citra dan proses akuisisi data. Pemeriksaan menggunakan CT Scan bertujuan untuk mengetahui ada atau tidaknya suatu kelainan pada organ tubuh manusia dengan menggunakan radiasi pengion, tanpa harus melakukan pembedahan sehingga didapat hasil diagnosis yang lebih tepat [1].

Citra yang dihasilkan oleh CT Scan termasuk dalam tipe citra digital. Citra digital merupakan citra yang dihasilkan dari pengolahan dengan menggunakan komputer, dengan cara merepresentasikan citra secara numerik. Citra tersebut ditampilkan dalam bentuk matrik (kolom dan baris). Satu elemen matrik disebut picture element (pixel) yang menunjukkan nilai tingkat keabuan (grey level) dari elemen citra tersebut [2].

Dalam pemeriksaan menggunakan CT Scan ada tiga parameter Scan yang berpengaruh terhadap dosis sinar-X yang dihasilkan yaitu tegangan tabung sinar- $\mathrm{X}(\mathrm{kV})$, arus waktu rotasi (mAs) dan ketebalan irisan dari objek (mm). Tegangan tabung dan arus waktu rotasi sinar-X menyebabkan perubahan dosis radiasi sinar-X, noise dan kontras citra [3]. Slice thickness adalah tebalnya irisan atau potongan objek yang diperiksa, umumnya ukuran tipis akan menghasilkan citra dengan resolusi yang rendah [4]. 
Noise citra CT Scan dinyatakan secara numerik yaitu pada standar deviasi dari CT Number. CT Number adalah nilai dari koefisien atenuasi sinar-X. Koefisien atenuasi ini adalah interaksi antara sinar-X terhadap material/bahan [5].

Penelitian yang dilakukan oleh Kofler pada Tahun 2016 [6] yang menyatakan bahwa pengukuran LCR (low contrast resolution) pada citra CT Scan menggunakan ukuran kuantitas rasio kontras terhadap noise yaitu CNR. CNR adalah salah satu metode pada Quality Control (QC) dalam CT Scan khususnya pada kualitas citra dan pemilihan slice thickness sangat berpengaruh pada hasil pencitraan.

Dari uraian tersebut, maka dilakukan penelitian mengenai pengaruh slice thickness terhadap kualitas citra CT Scan dengan parameter CNR menggunakan phantom. Penelitian ini dilakukan di Rumah Sakit Umum Daerah (RSUD) Bali Mandara dengan menggunakan data eksperimen dari hasil eksposi terhadap phantom. Selanjutnya ditentukan pengaruh slice thickness terhadap nilai CNR pada masing-masing ROI.

\section{Landasan Teori}

\subsection{CT Scan}

CT Scan merupakan salah satu alat pencitraan medis yang memanfaatkan radiasi pengion berupa sinar-X, dengan CT Scan akan lebih banyak kelainan pada organ tubuh manusia yang dapat terdeteksi. CT Scan dapat mencitrakan objek 3D yang tersusun atas irisan gambar (tomography) yang dihasilkan dari perhitungan algoritma komputer [5].

CT Scan menggunakan penyinaran khusus dan hasil penyinaran tersebut akan diterima oleh sistem Analog to Digital Converter (A/DC) untuk diproses menjadi data digital sehingga diperoleh citra penampang dari tubuh pasien. Untuk itu, pasien dibaringkan di atas bed pemeriksaan yang secara perlahan-lahan dipindahkan ke dalam cincin CT Scan. Scanner berputar mengelilingi pasien pada saat scanning dengan sinar-X. Waktu yang digunakan sampai seluruh proses scanning selesai berkisar antara 45 menit sampai 1 jam tergantung pada jenis CT Scan yang digunakan [7].

\subsection{Kualitas citra}

Kualitas citra yang berkualitas memberikan diagnosa yang akurat, hal ini agar meminimalisir kesalahan diagnosa akibat dari kualitas citra yang buruk. Kualitas citra dapat dijaga dengan melakukan QC dari perangkat Computed Radiography (CR). QC dilakukan saat tes penerimaan maupun uji fungsi rutin. Beberapa uji kontrol dalam CT Scan yaitu uji resolusi kontras, uji resolusi spasial maupun penghapusan noise. Dalam hal ini fisikawan medik memegang peranan penting sebagai petugas QC di instalasi radiologi [2]

Komponen yang mempengaruhi kualitas citra pada CT Scan adalah resolusi spasial, resolusi kontras, dan noise. Resolusi spasial adalah kemampuan untuk dapat membedakan objek yang berukuran kecil dengan densitas yang berbeda pada latar belakang yang sama. Kontras resolusi adalah kemampuan untuk menampilkan objek dalam ukuran 2-3 $\mathrm{mm}$ yang memiliki perbedaan densitas. Noise adalah fluktuasi dari standar deviasi nilai CT Number pada jaringan atau materi. keseluruhan komponen yang mempengaruhi kualitas citra ini bergantung pada slice thickness yang digunakan [6].

Pada awalnya program American Collage of Radiology (ACR) melakukan pengukuran low contrast dengan menggunakan pengamatan fisika medis untuk menilai citra secara subjektif. Pengamatan ini berdasarkan pada ukuran objek minimum yang dapat diamati dengan beberapa kriteria yang ditentukan dan faktor noise. Faktor noise merupakan hal penting dalam pengukuran low contrast karena terdapat perbedaan sinyal antara objek dan backgorund. Kemudian ACR menggantikan pengamatan visual dengan ukuran kuantitas rasio kontras terhadap noise yaitu CNR sehingga menghilangkan subjektivitas pengamat fisikawan medis. CNR dapat ditentukan dengan membuat ROI pada objek citra hasil scan, maka CNR dapat dihitung dengan menggunakan persamaan [6].

$$
C N R=\frac{\left|\bar{x}_{o b}-\bar{x}_{b g}\right|}{\sigma}
$$

$\bar{x}_{o b}$ adalah nilai rata-rata pada ROI objek dalam satuan Houndsfield Unit (HU), $\bar{x}_{b g}$ adalah nilai ratarata pada ROI background (HU), dan $\sigma$ adalah nilai standar deviasi pada ROI background. Nilai CNR harus lebih besar dari 1.0 untuk protokol kepala dan perut orang dewasa sedangkan untuk protokol perut anak-anak harus lebih besar 0.4 dan lebih besar dari 0.7 untuk protokol kepala anak-anak [8]. 


\section{Metode Penelitian}

Penelitian dilakukan dengan menggunakan Pesawat CT Scan merk Canon 16 slice tipe Aquilion TSX 201A yang terdapat di Ruang Instalasi Radiologi RSUD Bali Mandara. Data yang diolah merupakan data primer hasil dari eksperimen yang diperoleh langsung dengan melakukan eksposi terhadap phantom. Phantom yang digunakan adalah jenis Toshiba (TOS) phantom dengan tipe PX78-01377. Terdapat 6 jenis material yang terkandung di dalam phantom yaitu udara, derlin, acrylic, nylon, polypropylene, dan air. Pengambilan data pada penelitian ini dimulai dengan mempersiapkan peralatan yang digunakan yaitu CT Scan, head holder, phantom dan komputer. Faktor eksposi yang digunakan adalah $80 \mathrm{kV}, 100 \mathrm{mAs}$ dan variasi slice thickness yaitu 1,2,3,4, 6 dan $8 \mathrm{~mm}$. Selanjutnya dilakukan eksposi atau penyinaran terhadap phantom. Kemudian dilakukan pembacaan nilai ROI hasil citra dengan 5 kali pengulangan. Hasil scanning phantom pada slice thickness $1 \mathrm{~mm}$, serta proses pembacaan nilai nilai $\bar{x}_{o b}, \bar{x}_{b g}$ dan $\sigma$ pada ROI ditunjukkan pada Gambar 1.

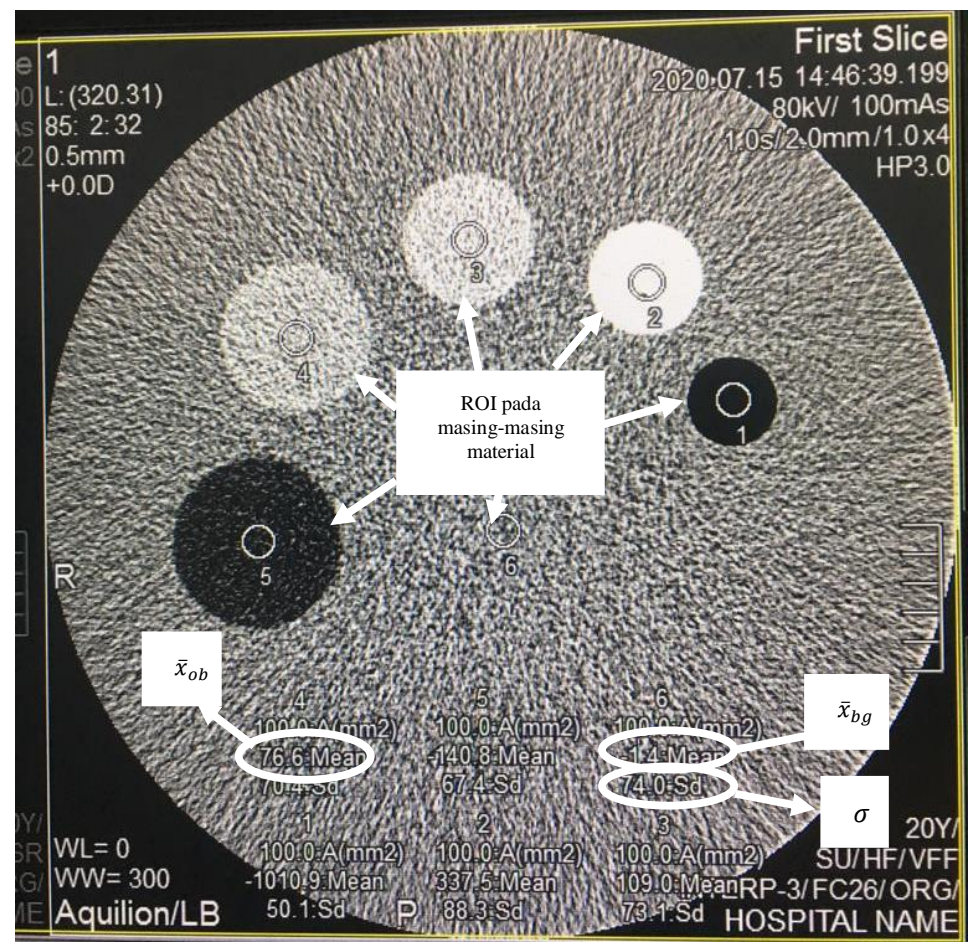

Gambar 1. Proses pembacaan nilai $\bar{x}_{o b}, \bar{x}_{b g}$ dan $\sigma$ pada masing-masing ROI.

Data yang diolah adalah citra phantom yang berisi nilai rata-rata ROI objek, background dan standar deviasi background. Data dikelompokkan menjadi empat jenis pada slice thickness yaitu nilai rata-rata dari masing-masing ROI pada slice thickness 1,2 , dan $3 \mathrm{~mm}$, nilai rata-rata dari masing-masing ROI pada slice thickness 4, 6 dan $8 \mathrm{~mm}$, nilai standar deviasi dari masing-masing ROI pada slice thickness 1, 2, dan $3 \mathrm{~mm}$ dan nilai standar deviasi dari masing-masing ROI pada slice thickness 4, 6, dan $8 \mathrm{~mm}$. Dari data tersebut dihitung nilai rata-rata total dari setiap ROI dan standar deviasi total background pada masing-masing slice thickness kemudian data dikelompokkan berdasarkan perbandingan antara ROI objek dengan ROI background. Setelah itu dapat dilakukan perhitungan nilai CNR dengan persamaan 1.

Analisis pengaruh variasi slice thickness terhadap kualitas citra CT Scan menggunakan microsoft excel dengan uji regresi sederhana dan dihasilkan grafik antara variasi slice thickness terhadap nilai CNR.

\section{Hasil Dan Pembahasan}

Hasil penelitian ini yaitu citra phantom seperti yang ditunjukkan pada Gambar 1, dari citra phantom tersebut ditentukan nilai rata-rata pada ROI dan standar deviasi pada masing-masing slice thickness. Nilai rata-rata ROI material pada slice thickness 1, 2 dan $3 \mathrm{~mm}$ ditunjukkan pada Tabel 1 dan Tabel 2. 
The Analysis of the Effect of Slice Thickness of Phantom on Image Quality of CT Scan

(Ida Ayu Putu Aristia Hutami, dkk)

Tabel 1. Nilai rata-rata ROI pada pada slice thickness 1,2 dan $3 \mathrm{~mm}$.

\begin{tabular}{|c|c|c|c|c|c|c|c|}
\hline \multirow{2}{*}{$\begin{array}{l}\text { Slice } \\
\text { thickness } \\
(\mathrm{mm})\end{array}$} & \multirow{2}{*}{$\begin{array}{l}\text { Percobaan } \\
\text { ke- }\end{array}$} & \multicolumn{6}{|c|}{ ROI masing-masing material pada phantom } \\
\hline & & a. Udara & b. Derlin & c. Acrylic & d. Nylon & e. Polypropylene & f. air \\
\hline \multirow{5}{*}{1} & 1 & $-1010,9$ & 337,5 & 109,0 & 76,6 & $-140,8$ & $-1,4$ \\
\hline & 2 & $-1020,1$ & 343,7 & 108,4 & 66,4 & $-137,7$ & 15,9 \\
\hline & 3 & $-1022,7$ & 349,3 & 114,0 & 66,9 & $-138,9$ & 14,3 \\
\hline & 4 & $-1015,3$ & 335,0 & 107,8 & 75,4 & $-145,0$ & 1,5 \\
\hline & 5 & $-1009,6$ & 342,1 & 114,9 & 77,4 & $-139,7$ & 15,4 \\
\hline \multirow{5}{*}{2} & 1 & $-1003,7$ & 340,6 & 107,0 & 71,4 & $-139,1$ & 3,7 \\
\hline & 2 & $-1006,9$ & 337,7 & 105,7 & 67,9 & $-135,5$ & $-0,1$ \\
\hline & 3 & $-1004,6$ & 341,9 & 108,5 & 67,7 & $-135,9$ & $-6,6$ \\
\hline & 4 & $-1010,2$ & 334,4 & 105,0 & 61,1 & $-136,7$ & 5,0 \\
\hline & 5 & $-1003,5$ & 341,5 & 97,5 & 64,5 & $-130,7$ & 2,7 \\
\hline \multirow{5}{*}{3} & 1 & $-1015,9$ & 341,3 & 108,0 & 67,2 & $-139,3$ & 5,1 \\
\hline & 2 & $-1017,9$ & 349,8 & 114,2 & 67,0 & $-144,0$ & 5,9 \\
\hline & 3 & $-1013,0$ & 346,5 & 114,0 & 68,9 & $-143,3$ & 7,2 \\
\hline & 4 & $-1041,7$ & 340,6 & 112,4 & 71,2 & $-136,9$ & 5,0 \\
\hline & 5 & $-1013,3$ & 341,0 & 107,1 & 73,4 & $-139,7$ & 11,7 \\
\hline
\end{tabular}

Tabel 2. Nilai rata-rata ROI pada pada slice thickness 4, 6 dan $8 \mathrm{~mm}$.

\begin{tabular}{cccccccc}
\hline \multirow{2}{*}{$\begin{array}{l}\text { Slice } \begin{array}{l}\text { thickness } \\
(\mathrm{mm})\end{array} \\
\text { ke- }\end{array}$} & $\begin{array}{l}\text { Percobaan } \\
\text { ke- }\end{array}$ & a. Udara & b. Derlin & c. Acrylic & d. Nylon & e. Polypropylene & f. air \\
\cline { 3 - 7 } & 1 & $-1004,6$ & 334,9 & 108,7 & 70,6 & $-138,1$ & 4,0 \\
4 & 2 & $-1005,7$ & 335,9 & 105,6 & 73,5 & $-138,0$ & 2,8 \\
& 3 & $-1007,5$ & 330,9 & 102,8 & 72,4 & $-140,5$ & 7,5 \\
& 4 & $-1008,5$ & 332,8 & 110,0 & 70,7 & $-140,9$ & 0 \\
& 5 & $-1007,3$ & 334,3 & 107,6 & 68,7 & $-138,3$ & $-2,6$ \\
& 1 & $-1004,2$ & 335,5 & 106,2 & 75,2 & $-137,6$ & 0,8 \\
6 & 2 & $-1002,8$ & 343,9 & 106,1 & 69,7 & $-143,5$ & 3,7 \\
& 3 & $-1004,9$ & 343,2 & 106,6 & 70,9 & $-139,9$ & $-1,0$ \\
& 4 & $-1007,4$ & 332,7 & 105,4 & 69,9 & $-137,7$ & $-2,7$ \\
& 5 & $-1004,0$ & 328,8 & 104,1 & 68,4 & $-142,7$ & 2,8 \\
& 1 & $-999,7$ & 330,3 & 102,5 & 67,6 & $-135,1$ & 1,6 \\
& 2 & $-1001,3$ & 327,4 & 103,8 & 69,8 & $-140,7$ & 1,4 \\
& 3 & $-998,8$ & 327,1 & 104,2 & 70,6 & $-136,0$ & $-0,7$ \\
& 4 & $-999,8$ & 332,7 & 103,5 & 70,3 & $-137,0$ & 0,7 \\
\hline
\end{tabular}

Nilai standar deviasi background yaitu ROI air pada pada keseluruhan slice thickness ditunjukkan pada Tabel 3.

Tabel 3. Standar deviasi dari ROI air pada masing-masing slice thickness.

\begin{tabular}{cccccc}
\hline $\begin{array}{c}\text { Slice thickness } \\
(\mathrm{mm})\end{array}$ & \multicolumn{5}{c}{ Percobaan ke } \\
\cline { 2 - 6 } & 1 & 2 & 3 & 4 & 5 \\
\hline 1 & 74,0 & 70,8 & 74,6 & 78,6 & 69,0 \\
2 & 61,2 & 60,7 & 60,9 & 67,5 & 63,9 \\
3 & 5,1 & 64,7 & 59,8 & 61,8 & 61,4 \\
4 & 46,9 & 45,2 & 45,2 & 44,0 & 46,3 \\
6 & 39,6 & 40,3 & 36,5 & 41,6 & 43,4 \\
8 & 30,3 & 27,8 & 29,6 & 26,8 & 30,1 \\
\hline
\end{tabular}

Dari Tabel 1, Tabel 2, Tabel 3 dilakukan perhitungan dengan menentukan rata-rata total dan standar deviasi total dari ROI objek dan background maka dapat dilakukan perhitungan CNR. Perhitungan CNR menggunakan rata-rata total dari ROI kelima material yaitu udara, derlin, acrylic, nylon, dan polyproylene, Kelima objek ini dibandingkan dengan standar deviasi total dari air pada masing-masing 
slice thickness. Hasil nilai CNR pada perbandingan ROI udara terhadap air ditunjukkan pada Tabel 4. Hasil nilai CNR pada perbandingan ROI derlin terhadap air ditunjukkan pada Tabel 5, hasil nilai CNR pada perbandingan ROI acrylic terhadap air ditunjukkan pada Tabel 6, hasil nilai CNR pada perbandingan ROI nylon terhadap air ditunjukkan pada Tabel 7 dan hasil nilai CNR pada perbandingan ROI polypropylene terhadap air ditunjukkan pada Tabel 8.

Tabel 4. Nilai CNR pada perbandingan ROI udara terhadap air.

\begin{tabular}{ccccc}
\hline $\begin{array}{c}\text { Slice thickness } \\
(\mathrm{mm})\end{array}$ & $\begin{array}{c}\text { Rata-rata } \\
\text { objek (HU) }\end{array}$ & $\begin{array}{c}\text { Rata-rata } \\
\text { background }(\mathrm{HU})\end{array}$ & $\begin{array}{c}\text { SD } \\
\text { background }\end{array}$ & CNR \\
\hline 1 & 1015,72 & 9,70 & 73,40 & 13,70 \\
2 & 1005,78 & 3,62 & 62,84 & 15,94 \\
3 & 1014,96 & 6,98 & 50,56 & 19,94 \\
4 & 1006,72 & 3,38 & 45,52 & 22,04 \\
6 & 1004,66 & 2,20 & 40,28 & 24,88 \\
8 & 999,86 & 0,90 & 28,92 & 34,54 \\
\hline
\end{tabular}

Tabel 5. Nilai CNR pada perbandingan ROI derlin terhadap air.

\begin{tabular}{ccccc}
\hline $\begin{array}{c}\text { Slice thickness } \\
(\mathrm{mm})\end{array}$ & $\begin{array}{c}\text { Rata-rata } \\
\text { objek }(\mathrm{HU})\end{array}$ & $\begin{array}{c}\text { Rata-rata } \\
\text { background }(\mathrm{HU})\end{array}$ & $\begin{array}{c}\text { SD } \\
\text { background }\end{array}$ & CNR \\
\hline 1 & 341,52 & 9,70 & 73,40 & 4,52 \\
2 & 339,22 & 3,62 & 62,84 & 5,34 \\
3 & 343,84 & 6,98 & 50,56 & 6,67 \\
4 & 333,76 & 3,38 & 45,52 & 7,25 \\
6 & 336,82 & 2,20 & 40,28 & 8,30 \\
8 & 328,94 & 0,90 & 28,92 & 11,34 \\
\hline
\end{tabular}

Tabel 6. Nilai CNR pada perbandingan ROI acrylic terhadap air.

\begin{tabular}{ccccc}
\hline $\begin{array}{c}\text { Slice thickness } \\
(\mathrm{mm})\end{array}$ & $\begin{array}{c}\text { Rata-rata } \\
\text { objek }(\mathrm{HU})\end{array}$ & $\begin{array}{c}\text { Rata-rata } \\
\text { background }(\mathrm{HU})\end{array}$ & $\begin{array}{c}\text { SD } \\
\text { background }\end{array}$ & CNR \\
\hline 1 & 110,82 & 9,70 & 73,40 & 1,38 \\
2 & 104,74 & 3,62 & 62,84 & 1,60 \\
3 & 111,14 & 6,98 & 50,56 & 2,06 \\
4 & 106,94 & 3,38 & 45,52 & 2,27 \\
6 & 105,68 & 2,20 & 40,28 & 2,57 \\
8 & 103,58 & 0,90 & 28,92 & 3,55 \\
\hline
\end{tabular}

Tabel 7. Nilai CNR pada perbandingan ROI nylon terhadap air.

\begin{tabular}{ccccc}
\hline $\begin{array}{c}\text { Slice thickness } \\
(\mathrm{mm})\end{array}$ & $\begin{array}{c}\text { Rata-rata } \\
\text { objek }(\mathrm{HU})\end{array}$ & $\begin{array}{c}\text { Rata-rata } \\
\text { background }(\mathrm{HU})\end{array}$ & $\begin{array}{c}\text { SD } \\
\text { background }\end{array}$ & CNR \\
\hline 1 & 72,54 & 9,70 & 73,40 & 0,86 \\
2 & 66,52 & 3,62 & 62,84 & 1,00 \\
3 & 69,54 & 6,98 & 50,56 & 1,24 \\
4 & 71,18 & 3,38 & 45,52 & 1,48 \\
6 & 70,82 & 2,20 & 2,20 & 1,70 \\
8 & 69,80 & 0,90 & 0,90 & 2,38 \\
\hline
\end{tabular}

Tabel 8. Nilai CNR pada perbandingan ROI polypropylene terhadap air.

\begin{tabular}{ccccc}
\hline $\begin{array}{c}\text { Slice thickness } \\
(\mathrm{mm})\end{array}$ & $\begin{array}{c}\text { Rata-rata } \\
\text { objek (HU) }\end{array}$ & $\begin{array}{c}\text { Rata-rata } \\
\text { background }(\mathrm{HU})\end{array}$ & $\begin{array}{c}\text { SD } \\
\text { background }\end{array}$ & CNR \\
\hline 1 & 140,32 & 9,70 & 73,40 & 1,78 \\
2 & 135,58 & 3,62 & 62,84 & 2,10 \\
3 & 140,64 & 6,98 & 50,56 & 2,64 \\
4 & 139,16 & 3,38 & 45,52 & 2,98 \\
6 & 140,28 & 2,20 & 2,20 & 3,42 \\
8 & 137,46 & 0,90 & 0,90 & 4,72 \\
\hline
\end{tabular}


Selanjutnya, dari Tabel 4 sampai 8 dapat dibuat grafik pengaruh slice thickness terhadap nilai CNR pada masing-masing ROI, seperti ditunjukkan pada Gambar 2, dan nilai coefficient of determination $\left(\mathrm{R}^{2}\right)$ ditunjukkan pada Tabel 6 .

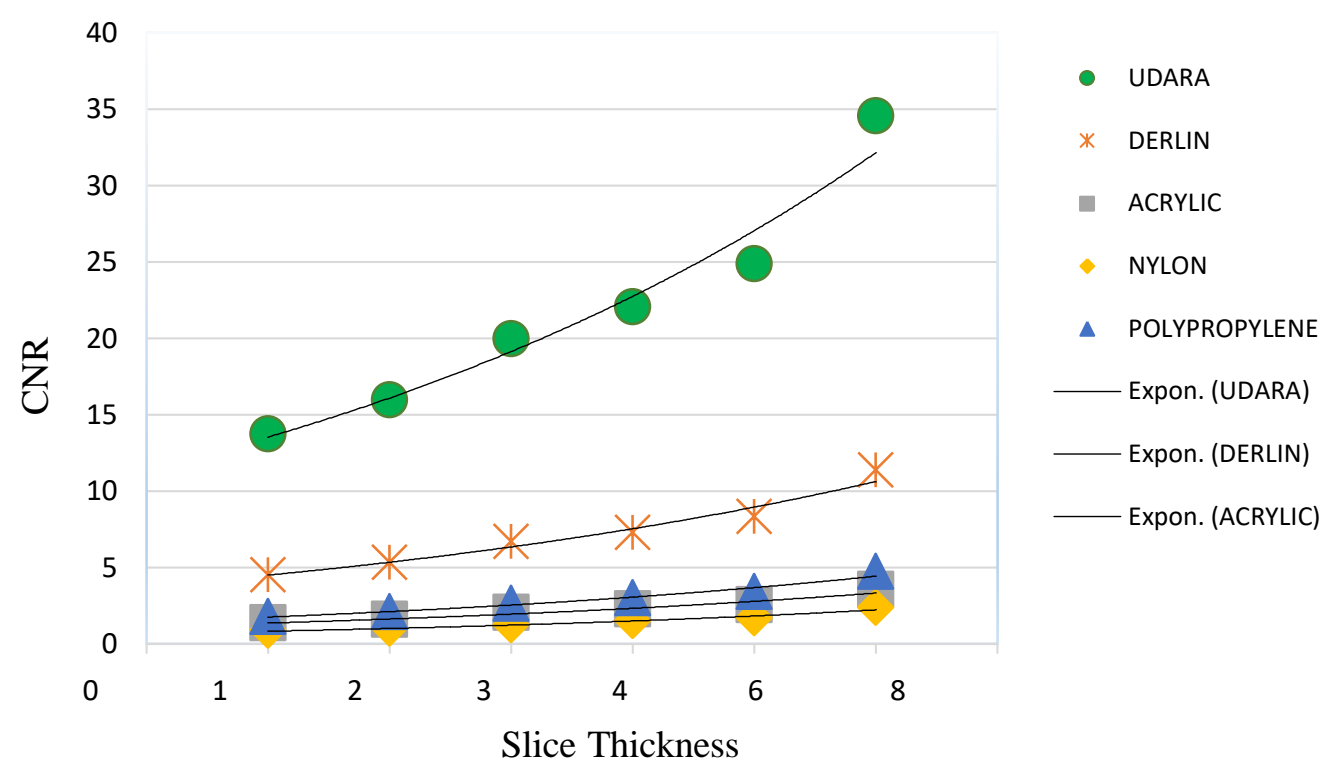

Gambar 2. Grafik hubungan antara slice thickness (Sumbu X) terhadap nilai CNR (Sumbu Y).

Tabel 9. Fungsi hubungan (y) dan koefisien determinasi $\left(\mathrm{R}^{2}\right)$.

\begin{tabular}{lllll}
\hline Udara & Derlin & Acrylic & Nylon & Polypropylene \\
\hline $\mathrm{y}=11,387 \mathrm{e}^{0.1731 \mathrm{x}}$ & $\mathrm{y}=3,7949 \mathrm{e}^{0.1717 \mathrm{x}}$ & $\mathrm{y}=1,144 \mathrm{e}^{0.1782 \mathrm{x}}$ & $\mathrm{y}=0,6838 \mathrm{e}^{0.1971 \mathrm{x}}$ & $\mathrm{y}=1,4642 \mathrm{e}^{0.1848 \mathrm{x}}$ \\
$\mathrm{R}^{2}=0,9722$ & $\mathrm{R}^{2}=0,9744$ & $\mathrm{R}^{2}=0,9745$ & $\mathrm{R}^{2}=0,9846$ & $\mathrm{R}^{2}=0,9811$ \\
\hline
\end{tabular}

Pada Tabel 9 menujukkan nilai koefisien determinasi $\left(\mathrm{R}^{2}\right)$ dari masing-masing material, pada udara sebesar 0,9722, derlin sebesar 0,9744, acrylic sebesar 0,9745, nylon sebesar 0,9846, dan polypropylene sebesar 0,9811, artinya tebal slice thickness mempengaruhi nilai CNR yaitu sebesar 97,46\% pada udara, 97,44\% pada derlin, $97,45 \%$ pada acrylic, $98,46 \%$ pada nylon, dan $98,11 \%$ pada polypropylene.

Selain itu, didapatkan persamaan regresi berdasarkan rumus $\mathrm{y}=\mathrm{a} e^{b x}$. Pada udara yaitu $\mathrm{y}=11,387 e^{0,1731 \mathrm{x}}$ dengan $\mathrm{y}$ adalah nilai CNR, $\mathrm{x}$ adalah slice thickness, 11,387 adalah konstanta, dan 0,1731 adalah koefisien regresi. Pada derlin yaitu $\mathrm{y}=3,7949 e^{0,1717 \mathrm{x}}$ dengan y adalah nilai CNR, $\mathrm{x}$ adalah slice thickness, 3,7949 adalah konstanta, dan 0,1731 adalah koefisien regresi. Pada acrylic yaitu $\mathrm{y}=1,144 e^{0,1782 \mathrm{x}}$ dengan $\mathrm{y}$ adalah nilai $\mathrm{CNR}$, $\mathrm{x}$ adalah slice thickness, 1,144 adalah konstanta, dan 0,1717 adalah koefisien regresi. Pada nylon yaitu $\mathrm{y}=0,683 e^{0,1971 \mathrm{x}}$ dengan $\mathrm{y}$ adalah nilai $\mathrm{CNR}, \mathrm{x}$ adalah slice thickness, 0,683 adalah konstanta, dan 0,1971 adalah koefisien regresi dan pada polypropylene yaitu $\mathrm{y}=1,4642 e^{0,1848 \mathrm{x}}$ dengan $\mathrm{y}$ adalah nilai CNR, $\mathrm{x}$ adalah slice thickness, 1,4642 adalah konstanta, dan 0,1848 adalah koefisien regresi.

Pada Tabel 1 yaitu nilai CNR ROI udara menghasilkan nilai terendah yaitu 13,70 dan tertinggi 34,54. Pada Tabel 2 yaitu nilai CNR ROI derlin menghasilkan nilai terendah yaitu 4,52 dan tertinggi 11,34. Pada Tabel 3 yaitu nilai CNR ROI acrylic menghasilkan nilai terendah yaitu 1,38 dan tertinggi 3,55. Pada Tabel 4 yaitu nilai CNR ROI nylon menghasilkan nilai terendah yaitu 0,86 dan tertinggi 2,38 dan pada Tabel 5 yaitu nilai CNR ROI polypropylene menghasilkan nilai terendah yaitu 1,78 dan tertinggi 4,72 .

Pada Gambar 2 ditunjukkan bahwa adanya perubahan nilai CNR akibat dari tebal slice thickness. Semakin besar slice thickness maka nilai CNR semakin besar dan kualitas citra yang semakin baik. Penggunaan slice thickness sangat mempengaruhi kualitas citra dan berdasarkan Gambar 2 tersebut dapat diamati bahwa antara slice thickness dengan CNR memiliki pengaruh yang kuat. Hal ini disebabkan karena perbandingan rasio kontras terhadap noise dan slice thickness inilah yang mempunyai peranan penting dalam menentukan nilai CNR. Saat digunakannya slice thickness yang tipis menghasilkan nilai 
CNR minimum, sedangkan pada penggunaan slice thickness yang tebal akan menghasilkan nilai CNR maksimum. Hasil ini mendukung penelitian yang dilakukan oleh Nuryahati pada tahun 2019 [3] yang menyatakan bahwa penggunaan slice thickness mempengaruhi nilai noise pada citra, yaitu semakin tipis slice thickness kualitas citra akan menurun, disebabkan oleh banyaknya noise sedangkan semakin tebal slice thickness kualitas citra akan meningkat karena sedikitnya noise.

Besar kecilnya ukuran slice thickness pada pemeriksaan medis ini tergantung pada kebutuhan diagnosis dari objek yang diperiksa [11]. Setelah mengetahui bahwa slice thickness merupakan faktor yang sangat penting dalam penggunaan CT Scan maka perlu adanya quality control dan quality accuracy untuk evaluasi slice thickness dan parameter lainnya pada CT Scan sesuai dengan Peraturan BAPETEN Nomor 2 Tahun 2018 Tentang Uji Kesesuaian Pesawat Sinar-X Radiologi Diagnostik dan Intervensional.

\section{Kesimpulan}

Berdasarkan hasil dan pembahasan, maka dapat disimpulkan bahwa slice thickness berpengaruh terhadap nilai CNR. Semakin besar slice thickness maka nilai CNR semakin besar dan kualitas citra yang semakin baik.

\section{Ucapan Terima Kasih}

Ucapan terima kasih ditujukan kepada staff Rumah Sakit Umum Daerah Bali Mandara atas izin dan bantuan dalam pelaksanaan penelitian maupun penulisan, sehingga publikasi ini dapat selesai sebagaimana mestinya.

\section{Pustaka}

[1] D. Aprilyanti, D Milvita, H.Prasetio, H. Yulianti, Pengaruh Diameter Phantom dan Tebal Slice Terhadap Nilai CTDI Pada Pemeriksaan Menggunakan CT-Scan, Jurnal Fisika Unand, vol.2, no. 2, 2013, pp 81-87.

[2] A. Mei Yusnida, Suryono, Uji Image Uniformity Perangkat Computed Radiography Dengan Metode Pengolahan Citra Digital, Youngster Physics Journal, vol. 3, no. 4, 2014, pp 251-255.

[3] A. Nurhayati, Nia N. Nariswari, B. Rahayuningsih, Yuda. C. Hariadi, Analisis Variasi Faktor Eksposi dan Ketebalan Irisan Terhadap CTDI dan Kualitas Citra Pada Computed Tomography Scan, Berkala Sainstek, vol. 2, no 3, 2019, pp 7-12.

[4] Seeram E.,Computed Tomography Physical Principles, Clinical Applications and Quality Control. W.B Saunders Company, 2001, pp 327-329.

[5] A. A. Lestari, H. Susanto, Z. Arifin, Analisis Noise Level Hasil Citra CT Scan Pada Tegangan Tabung $120 \mathrm{kV}$ dan $135 \mathrm{kV}$ Dengan Variasi Ketebalan Irisan (Slice Thickness), Youngster Physics Journal, vol. 3, no. 3, 2014, pp 189-195.

[6] Kofler, J. M, L. Yu, S. Leng, Y. Zhang, Z. Li, R. E. Carter, C. H. McCollough. Assessment of low contrast resolution fir he ACR CT accreditation program: what is the impact of iterative reconstruction. HHS Public Access Author Manuscript. vol. 39, no. 4, 2016, pp 619-623.

[7] E. S. B Siregar, G.N. Sutapa, I. W. B. Sudarsana, Pemantauan Dosis Efektif Pada Pemeriksaan CT Scan Kepala Anak Dengan Software IndoseCT, Kappa Journal, vol. 3, no.2, 2019, pp 113-117.

[8] N. N. Nariswari, Analisis Variasi Faktor Eksposi dan Ketebalan Irisan Terhadap CTDI dan Kualitas Citra Pada Computed Tomography (CT) Scan, [Skripsi], Jurusan Fisika, Fakultas Matematika dan Ilmu Pengetahuan Alam, Universitas Jember, 2018.

[9] American College of Radiology (ACR). American College of Radiology CT Accrediation Program Testing Instructions. New York. American Institute of Physics, 2018.

[10] T. Meilinda, E. Hidayanto, Z. Arifin, Pengaruh Perubahan Faktor Eksposi Terhadap Nilai CT Number, Youngster Physics Journal, vol. 3, no. 3, 2014, pp 269-278.

[11] Hasnani, Analisis Resolusi Kontras Citra CT Scan menggunakan Phantom American College of Radiology (ACR), [Skripsi], Departemen Fisika, Fakultas Matematika dan Ilmu Pengetahuan Alam, Universitas Hasanuddin, Makassar, 2017. 